\title{
Morphological Studies on the Choroid Plexus in Balady Goat (Capra hircus)
}

\section{Safwat Ebada ; Amr Helal ${ }^{2}$ and Mohamed AlKafafy ${ }^{3}$}

1 Department of Anatomy and embryology, Faculty of Vet. Med., Mansoura University, Egypt.

2 Department of Anatomy and embryology, Faculty of Vet. Med., Zagazig University, Egypt.

3 Department of Cytology and Histology, Faculty of Vet. Med., Minufiya University Sadat city branch, Egypt.

\section{Abstract}

The lateral ventricle choroid plexus could be subdivided according to its vascular pattern into caudal part, middle part and rostral part (villus fringes), The two narrow bands which arose from the choroid plexuses of the lateral ventricles passed in the interventricular foramen, forming the choroid plexus of the third ventricle, each band appeared under stereomicroscope as down folding liner tufts reaching the level of pineal body. The third and fourth ventricles choroid plexuses consisted of a large number of leaveslike processes connected to a more basal core of the stromal tissue by a stem. Secondary leaf-like elevations might arise from primary leaves. The stromal tissue extended into the leaves accompanied by vessels which brake up into capillary plexuses in the body of the leaves. The highly vascular stroma of the choroid plexus covered with a single layer of cuboidal epithelium almost ciliated, with an average height 9.55 $\mu \mathrm{m}$. The covering epithelium constitutes about $19.5 \%, 31.9 \%$ and $31.8 \%$ of the total bulk of the choroid plexuses of the lateral, third and fourth ventricles respectively. Relatively large amount of connective tissue separated the blood vessels from the epithelium representing about $30.1 \%$ of the total bulk of the lateral ventricle choroid plexus. While it represented about $28.7 \%$, and $39.8 \%$ in third and fourth ventricles choroid plexuses respectively, its main component was formed of collagen bundles. The connective tissue stroma sometimes appeared very thin that allowed apposing of the endothelium of the blood vessels with the basement membrane of the choroidal cells. The connective tissue stroma characterized by 
abundance of blood vessels. These blood vessels in the lateral ventricle were wide long, slightly tortuous and relatively parallel. The choroid plexus of the lateral ventricle was relatively highly vascular, the blood vessels represented about $49.8 \%$ of the total bulk of the lateral ventricle choroid plexus in comparison with the third ventricle choroid plexus (about $36.3 \%$ ) and fourth ventricle choroid plexus (about 28.3\%).

\section{Introduction}

The discovery of the choroid plexus of the encephalic ventricles was attributed by Galeno to Herophilus (335-280 A.C.) who named them "choroids menix". Rufos of Ephesus suggested the term "choroids tunic" to describe the ependyma as the choroid plexus (Dohrmann, 1970). The choroid plexuses consisted of vascular folds from the pia mater externally covered by an epithelium derived from the ependymal coating of the ventricles (Webster, 1976). There are four interconnected channels referred to as the ventricles that are filled with cerebrospinal fluid (CSF) within the central portions of the brain. The choroid plexuses exist within these ventricles where they produce the CSF and comprise a unique interface between the peripheral blood and the CSF (Jeon et al., 2005 and Christo- pher and Dwaine, 2007). The choroid plexus has two primary functions, production and regulation of the components of the CSF and inhibit entry of exogenous substance into the brain (Bill et al., 2008).

The available literature were concerned with choroid plexus of human (Serot et al. 2003), monkey (Tamega et al., 2000), rat (Peters, 1974), rabbit (Weiger et al., 1986) and cat (Miodonski et al., 1979) and there is a lack of information about choroid plexus in domestic animals. Thus, the objective of the present investigation was to examine the choroid plexuses of the goat, in comparison to that of other species, for better description.

\section{Materials and methods}

Ten heads of adult goats of both sexes were used in this study. The specimens were collected from Zagazig abattoirs. Seven heads were fixed by intra common carotid artery infusion with $10 \%$ neutral buffered formalin; four of them were used for the anatomical description. Choroid plexuses were dissected from the other three heads and used for the histological studies. Choroid plexus samples were processed by normal histological technique, sectioned at $5 \mu \mathrm{m}$ thickness, stained with hematoxylin and eosin, alcian blue/- 
periodic acid Schiff's reagent and trichrome stains adopted by (Bancroft and Stevens, 1990). For histomorphometric studies, eye-piece micrometer with $\mathrm{X} 20$ objective lens was used. Image $\mathrm{J}$ software used for stereological studies. Three goat heads were perfused with a warm normal saline solution, and then injected with an equal mixture of Indian ink and bovine serum (1:1) through the common carotid arteries. The injected specimens were fixed in $10 \%$ neutral buffered formalin solution for 1-2 weeks. The removed choroid plexuses were dehydrated in ascending grades of alcohol and cleared in benzol followed by an equal mixture of methyl benzoate and benzylbenzoate according to (Fath El-Bab et al., 1983). The prepared choroid plexuses were examined by the aid of binocular dissecting stereomicroscope.

\section{Results}

\section{Anatomical observations}

The lateral ventricle choroid plexus emerges at the inferior (temporal) horn of the lateral ventricle as a thin bright red strip of about $3 \mathrm{~mm}$ in width and $17 \mathrm{~mm}$ in length. Then it passes caudodorsally along the rostral border of the hippocampus then bends rostrodorsally at the ventrolateral part of the lateral ven- tricle and inclines ventrally to reach the rostral end of the hippocampus ventral to the genu of the corpus callosum and dorso-lateral to the caudate nucleus. It terminates before the rostral end of the rostral (frontal) horn of the lateral ventricle by about $5 \mathrm{~mm}$. (Figs. $1 \& 2$ ). Before its termination, the lateral ventricle choroid plexus gives off a narrow band which passes through the interventricular foramen. The two narrow bands, of both sides, fuse to give the choroid plexus of the third ventricle (Figs. $3 \& 4$ ).

The lateral ventricle choroid plexus can be subdivided according to its vascular pattern into caudal part, middle part and rostral part (villus fringes). At the entrance of the caudal choroidal artery into the caudal part, the choroid plexus appears thin, flat and its arterioles and venules are narrow, nearly straight, parallel and widely separated (Fig. 4). At the middle part of the choroid plexus the arterioles and venules appear more tortuous, relatively densely packed with variable diameter and the short anastomosis between the blood vessels are rarely observed (Fig. 5). Then rostrally, the blood vessels become less tortuous and aggregate to become more densely packed forming a narrow band (Fig. 6) passes through the interventricular foramen to join that 
of the opposite side forming the choroid plexus of the third ventricle (Figs. $3 \& 4$ ). The villus fringes located lateral to the middle part and extends rostrally beyond the level of the narrow band and interventricular foramen. It appears as leavesshaped plexuses (Fig. 7).

The two narrow bands which arise from the Choroid plexuses of the lateral ventricles pass in the interventricular foramen present between the thalamus and the rostral end of the hippocampus, they cross the latter to gain the third ventricle where they form the choroid plexus of the third ventricle. The two bands forming the choroid plexus of the third ventricle are thin rostrally ( 3 $\mathrm{mm}$ ) and demarcated dorsally by a longitudinal shallow groove, caudally they were thick $(6 \mathrm{~mm})$ and completely fused. The choroid plexus of the third ventricle is about $10 \mathrm{~mm}$ length, it is present in the dorsal part of the third ventricle and attached dorsally to the body of the corpus callosum and is related ventrally to the thalamus, lateral geniculate body and the rostral part of the rostral colliculus. Each band of the plexus appears under stereomicroscope as down-folding liner tufts reaching the level of pineal body (Figs. 4 \& 8)
The right and left choroid plexuses of the fourth ventricle appear in cicterna cerebellomedullaris, situated laterally in between the caudal part of the cerebellum and medulla oblongata. It is bright pinkish in color, oval in shape of about $4-5 \mathrm{~mm}$ in length, $3 \mathrm{~mm}$ in width and $3 \mathrm{~mm}$ in thickness. It is related and attached dorsally to the lobus dorsalis parafollicularis of the cerebellum and ventrally to the caudal cerbellar peduncle and the caudal third of the fourth ventricle, while rostrolaterally it is related to the lobulus follicularis and rostro-medially to cerebellar peduncle and caudolaterally to the lobus ansiformis and caudomedially to uvula (Fig. 9). The fourth ventricle choroid plexus shows tree-like branching, consisted of a large number of leaves-like processes connected to basal stem. Secondary leaf-like elevations may arise from primary leaves (Fig. 10).

\section{Histological observations}

The choroid plexus of the lateral ventricle at low magnification is represented by parallel folds with variable dimensions (Fig. 11). The third and fourth choroid plexuses consisted of large number of leaveslike processes connected to a more basal core of stromal tissue by a stem. Secondary leaf-like elevations may arise from primary leaves (Fig. 12). The stromal tissue extends into 
the leaves accompanied by vessels which break up into capillary plexuses in the body of the leaves (Fig. 13).

The highly vascular stroma of the choroid plexus is covered with a single layer of cuboidal to low columner epithelium (Fig. 13), with an average height $9.55 \mu \mathrm{m}$. However, due to the tree like branching of the third and fourth ventricle choroid plexuses, their epithelial covering was apparently larger than that of the lateral ventricle plexus. The covering epithelium constitutes about $19.5 \%, 31.9 \%$ and $31.8 \%$ of the total bulk of the choroid plexuses of the lateral, third and fourth ventricles, respectively. The cytoplasm of the cuboidal epithelium almost intensely stained with eosin and appears granular especially at the supranuclear region. The apical borders of some cells, exhibit microvilli and cilia while others appear bulged or exhibit secretory protrusions (Fig. 14). A second type of cells is observed at the luminal border of the choroidal plexus covering epithelium, these cells were characterized by scanty cytoplasm and a relatively dense irregular nucleus. Its long axis parallel is to the luminal surface of choroidal cells (Fig. 15). The cytoplasm exhibits negative reaction to $A B$ and is faintly stained with PAS (Fig. 16).
A relatively large amount of connective tissue separate the blood vessels from the choroidal epithelium representing about $30.1 \%$ of the total bulk of the lateral ventricle choroid plexus. While it represents about $28.7 \%$, and $39.8 \%$ in third and fourth ventricles choroid plexuses, respectively (table 1). The main stromal component is represented by collagen bundles (Fig. 17). The connective tissue stroma sometimes appears so thin that allow apposing of the endothelium of the vessels with the basement membrane of the choroidal epithelium (Figs. $13 \& 15$ ). The connective tissue stroma is characterized by presence of abundant blood vessels. These blood vessels in the lateral ventricle are wide long, slightly tortuous and relatively parallel (Fig. 11). The choroid plexus of the lateral ventricle is relatively highly vascular. The blood vessels represented about $49.8 \%$ of the total bulk of the lateral ventricle choroid plexus in comparison with the third ventricle choroid plexus (about 36.3\%) and fourth ventricle choroid plexus (about 28.3\%).

\section{Discussion}

Similar to other mammals: human (Snell, 1997 and Wilkinson, 1998), cattle, horse and dog (Dyce et al., 2002) and Monkey (Testut and La- 
tarjet, 1990). The choroid plexus of Capra hircus includes the choroid plexus of the lateral ventricles, third ventricle and fourth ventricle.

Similar to the findings in the dromedary (Mansour, 1983), the present study established that the choroid plexus of the lateral ventricle emerges at the ventral horn of the lateral ventricle then passes caudodorsally along the rostral border of the hippocampus and dorsolateral to the caudate neucleus.

The choroid plexus of the lateral ventricle terminates before the end of the rostral horn of the lateral ventricle. This is in agreement with that denoted in human by Young and Young (1997) and Strazielle and Ghersi-Egea (2000). However, Testut and Latarjat, (1990) in monkey stated that, it occupies the frontal portion of the lateral ventricle. The architecture of the choroid plexus in Capra hircus is similar to those obtained by Banks (1993) and Fawcett (1993).

Our results showed that, the constitution of the choroid plexus of the lateral ventricle under low magnification of light microscope appeared as parallel folds with variable dimensions. Such results is very similar to that described by Rajtova, (2002) in sheep, Scala et al. (1994) in goat and Tamega et al. (2000) in monkey under scanning electron microscope at low magnification.

According to the result of this study, the apical borders of some cells have microvilli and cilia while other appeared bulged or exhibited secretory protrusions. This result is supported by the findings of Rajtova (2002) in sheep, Adami et al. (2005) in horse and De Spiagelaere et al. (2008) in pig by using electron microscope. The later author noticed some cells with large depressions. However Peters (1974) in rat and Rajtova (2002) in sheep could not identify typical cilia on the ventricular surface of the choroid plexus. The outer morphology of choroid plexus surface in adult goat differs more substantially from that in the goat and sheep fetuses. In sheep and goat fetuses there are typical cilia beside microvilli scattered or arranged in tufts on the choroid plexus surface (Rajtova, 1997).

Our results show that, the vascularization of the lateral ventricle is higher than that of the third and fourth ventricles, these observations attributed to a more secretory activity of the choroid plexus in the lateral ventricle. This interprets the presence of small spherical or elongated protrusions of secretion observed only in the lateral ventricle choroid 
plexus under scanning electron microscope in goat (Rajtova, 2000).

The cells observed on the surface of the choroid plexus epithelium in the present study were similar to epiplexus cells with cytoplasmic prolongations (Rajtova, 2002) in sheep, or with the expansions of the perikaryon (De Spiegelaere et al. 2008) in pig and Tamega et al. (2000) in monkey. These cells have their origin from the cellular elements of the connective tissue stroma (Biond, 1934 and Ariens -Kappers, 1958) in human. However Carpenter et al. (1970) in cat proposed that monocytes crossed the choroid blood vessels and then penetrate in the space of connective tissue, being then macrophages and consequently crossed the choroid epithelium to become epiplexus cells. The outer morphology of epiplexal cells in adult sheep (Rajtova 2002) and goat (Rajtova 2000), as well as in the fetal material from both species (Rajtova 1997) is the same.

\section{References}

Adami F. Faria MM Almeida AE, Pinto MG and Prada IL. (2005): Scanning electron microscopy choroids plexus of the lateral ventricle of the horse. Anat. Histol embryo. 34(6): 379-382.
Ariens-Kappers J. (1958): Structural and functional changes in the telencephalic choroid plexus during human ontogenesis. In CIBA foundation symposium on the cerebrospinal fluid. 3-31

Bancroft, GD. and Stevens, A. (1990): Theory and practice of histopathological technique. 4th ed., Churchill Livingstone, Edinburgh. London, Melbourne and New York.

Banks, WJ.(1993): Nervous system, In: Applied Veterinary Histology, 3rd ed., Mosby Year Book St. Louis, Baltimore, Boston ,Chicago ,London, Philadelphia, Sydney, Toronto, Pp243.

Bill, BR.; Balciunas, D.; McCarra, JA.; Young, ED.; Xiong, T.; Spahn, AM.; Garcia-Lecea, M.; Korzh, V.; Ekker, SC and Schimmenti, LA. (2008): Development and notch signaling requirements of the zebra fish choroid plexus. PLoS One. 3 (9): e3114

Biond G. (1934): Zur Histologie des Menschlichen Plexus Choroideus und des Ependyme. Arch. Psychiat Nervenkr 101: 666-728.

Carpenter SJ; McCarthy LE and Borison NL. (1970): Electron microscopic study of the epi- 
plexus (Kolmer) cells of the cat choroid plexus. Z Zellforsch Mikrosk Anat. 110: 471-486.

Christopher, GT. and Dwaine, FE. (2007): Choroid plexus epithelial cell transplants for repair of the brain. Elsevier Inc. LCT Biopharma, Inc., Providence, Rhode Island Pp 399-416.

De Spiegelaere W. Casteleyn C, Van Den Broeck W, and Simoens P. (2008): Electron microscopic study on the porcine choroid plexus epithelium. Anat. Histol embryo. 37(6): 458-463.

Dohrmann, GJ. (1970): The choroid plexus a historical review. Brain Res. 18:197-218.

Dyce, KM.; Sack, WO. and Wensing, CJG. (2002): Text book of veterinary anatomy. 3rd ed., chapter 8, Saunders Company, Philadelphia, London, New York, St. Louis, Sydney, Toronto. Pp. 295-305.

Fath El- Bab, MR.; Schwarz, R. and Godynicki, S. (1983): The morphogenesis of the vasculature in bovine fetal skin. J. Anat. 136: 561-572.

Fawcett, DW. (1993): Nervous tissue, In: Bloom and Fawcett, A textbook of histology. $12^{\text {th }}$ ed., Chapman and Hall, Pp. 360-365.

Jeon, JH; Lee, SW. and Ko, JK. (2005): Neuroendoscopic removal of large choroids plexus cyst: a case report. J. Korean Med. Sci. 20 (2): 335-9.

Mansour, AA. (1983): Some anatomical features of Systema nervosum centrale of Camelus dromedaries. PhD Thesis. (Anatomy), Faculty of Vet. Med., Assuit University.

Miodonski, A; Poborowska, J. and Friedhuber de Grubenthal, A. (1979): SEM Study of the choroid plexus of the lateral ventricle in the cat. Anat. Embryol (Berl). 155(3): 323331

Peters, A. (1974): The surface fine structure of choroid plexus and ependymal lining of the rat lateral ventricle. J. Neurocytology. 3 (1): 99-108.

Rajtova, V. (1997): Choroid plexus in sheep and goat: A Scanning electron microscope study. Acta Vet. Bron. 66: 167-171.

Rajtova, V. (2000): Plexus choroideus in the adult goat: Scanning electron microscopy of the fetuses. Acta Vet. Bron. 69: 199-202.

Rajtova, V. (2002): Scanning electron microscopy of plexus 
choroideus in adult sheep. Acta Vet. Bron. 71: 279-282.

Scala, G; Mirabella, N; Paino, G. and Pelagalli, GV. (1994): The microvascularization of the choroid plexus of the lateral ventricles in the goat (Capra hircus). Anat Histol Embryol. 23(2):93-101. (abstract).

Serot, JM.; Bene, MC. and Faure, GC. (2003): Choroid plexus, aging of the brain, and Alzheimer's disease. Frontiers in Bioscience. 8 (Suppl.): s515- s521.

Snell RS. (1997): Clinical neuroanatomy for medical students. $4^{\text {th }}$ ed. Georg Washington University School of Medicine and Health Science Washington, D.C.

Strazielle, N. and Ghersi-Egea, JF. (2000): Choroid plexus in the central nervous system: biology and physiopathology. J. Neuropathol. Exp. Neurol. 59(7): 561-574.

Tamega, OJ; Tirapelli, LF. and Petroni, S. (2000): Scanning electron microscopy study of choroids plexus in the monkey (Cebus paella paella). Arq Neuropsiquiatr. 58(3B):820-825.

Testut, L. and Latarjet, A. (1990): Tratado de anatomia huma-
na.Barcelona:salvat. (Cited by Tamega et al., 2000)

Webster, HF. (1976): Choroid plexus. In Peters A, Palay SL, Webster, HF: The fine structure of the nervous system: The neurons and supporting cells. Philadelphia, Saunders. Pp.280-294.

Weiger, T; Lametschwandtner, A; Hodde, KC. and Adam, $\mathrm{H}$. (1986): The angioarchitecture of the choroid plexus of the lateral ventricle of the rabbit: A scanning electron microscopic study of vascular corrosion casts. Brain Res. 378 (2): 285-296.

Wilkinson, JL. (1998): Neuroanatomy for medical students. Chapter $13,3^{\text {rd }}$ ed., Butterworth, Heinemann, Oxford, Boston, Johannesburg, Melbourne, New Delhi and Singapore. Pp189-199.

Young, PA. and Young, PH. (1997):

Basic clinical neuroanatomy $1^{\text {st }}$ ed., Williams \&Wilkins. Warmly Comp, Baltimore, Philadelphia, London and Paris. 
Table (1): Stereological analysis of the choroidal plexus components:

\begin{tabular}{lccc}
\hline Components & $\begin{array}{c}\text { Lateral ventricle } \\
\text { choroid plexus }\end{array}$ & $\begin{array}{c}\text { Third ventricle } \\
\text { choroid plexus }\end{array}$ & $\begin{array}{c}\text { Fourth ventricle } \\
\text { choroid plexus }\end{array}$ \\
\hline Epithelial covering & $19.5 \% \pm 0.85$ & $31.9 \% \pm 0.77$ & $31.8 \% \pm 0.89$ \\
Vasculature & $49.8 \% \pm 0.76$ & $36.3 \% \pm 0.9$ & $28.3 \% \pm 0.69$ \\
$\begin{array}{l}\text { Connective tissue } \\
\text { stroma }\end{array}$ & $30.1 \% \pm 0.65$ & $28.7 \% \pm 0.69$ & $39.8 \% \pm 0.59$ \\
\hline
\end{tabular}
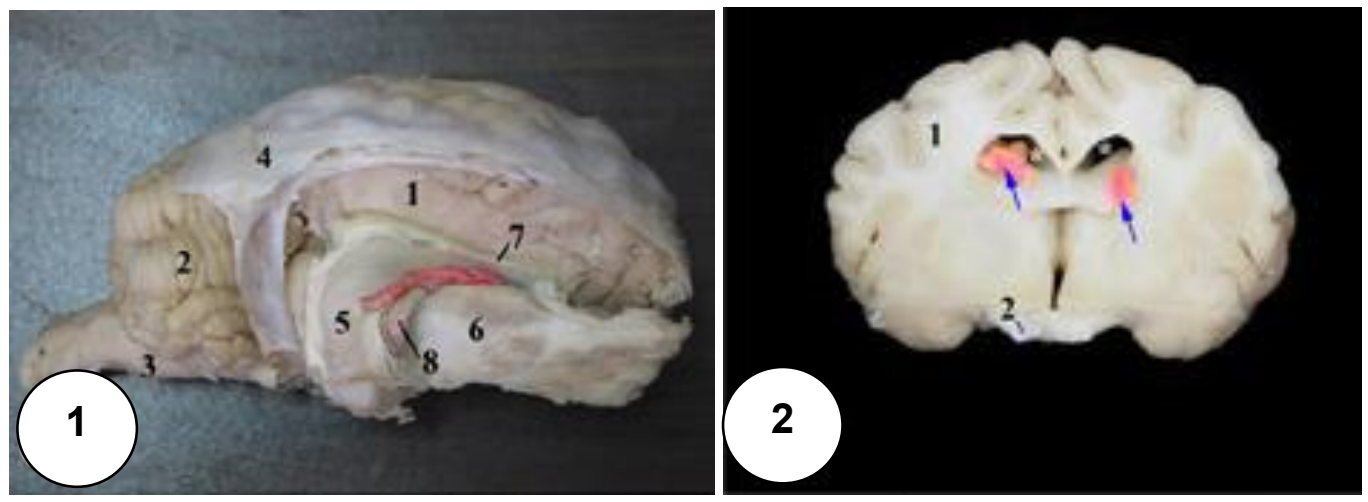

Fig. (1): Lateral view of the brain of goat after removal of the right cerebral hemisphere and its covering meninges showing the choroid plexus of the lateral ventricle (colored dotted area), left cerebral hemisphere (1), cerebellum (2), medulla oblongata (3), meninges (4), Hippocampus (5), caudate nucleus (6), genu of the corpus callosum (7) and fimbria of hippocampus (8) .

Fig. (2): Coronal section of goat brain at the level of optic chiasma showing, choroid plexus of the lateral ventricle (arrow), lateral ventricle (asterisk), cerebral hemisphere (1) and optic chiasma (2). 

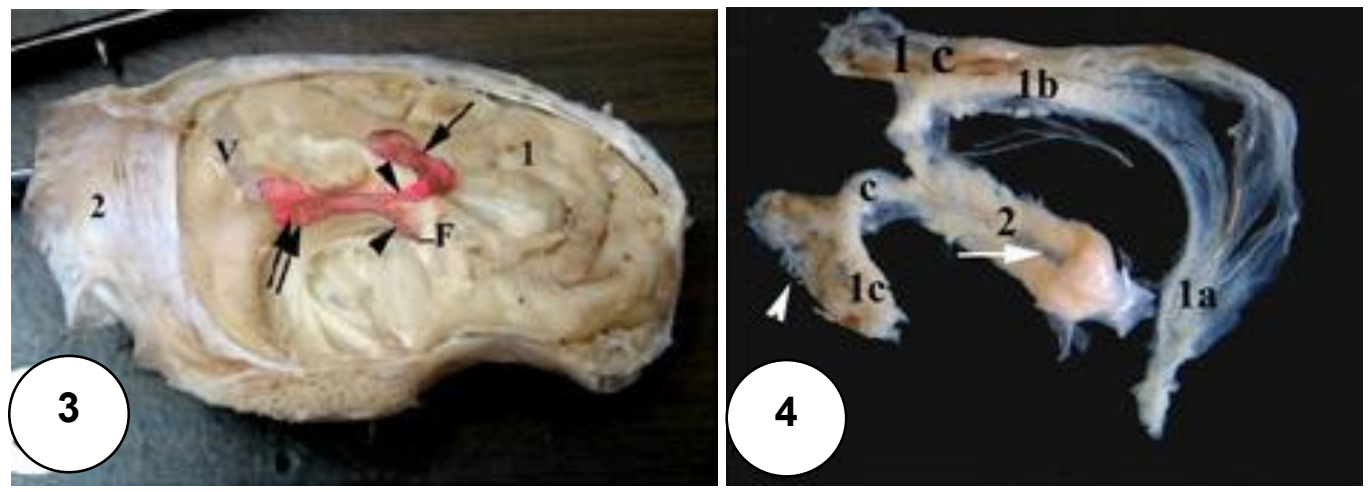

Fig. (3): Ventrolateral view of sagittal section of goat brain, after removal of hippocampus, caudate nucleus, thalamus and lateral geniculate body showing choroid plexus of the lateral ventricle reflected dorsomedially (arrow), narrow band between the choroid plexus of the lateral and third ventricle (arrow heads), choroid plexus of the third ventricle (double arrow) and dorsal cerebral vein (V), cerebellar hemisphere (1) Meninges (2) and interventricular foramen (F). (The choroid plexuses dotted and highlighted with red color).

Fig. (4): Photomacrograph of the choroid plexus in the lateral and third ventricles by stereomicroscope showing the caudal part (1a), middle part (1b) and the rostral part (1c) of the lateral ventricle choroid plexus, the narrow band between the third and lateral ventricle choroid plexuses (C), third ventricle choroid plexus (2). Note the fringes (arrow head) of the lateral ventricle choroid plexus and the dorsal longitudinal groove of the third ventricle choroid plexus (arrow). (the middle and caudal parts of the left lateral ventricle were removed). Using stereomicroscope $\mathrm{X} 4$
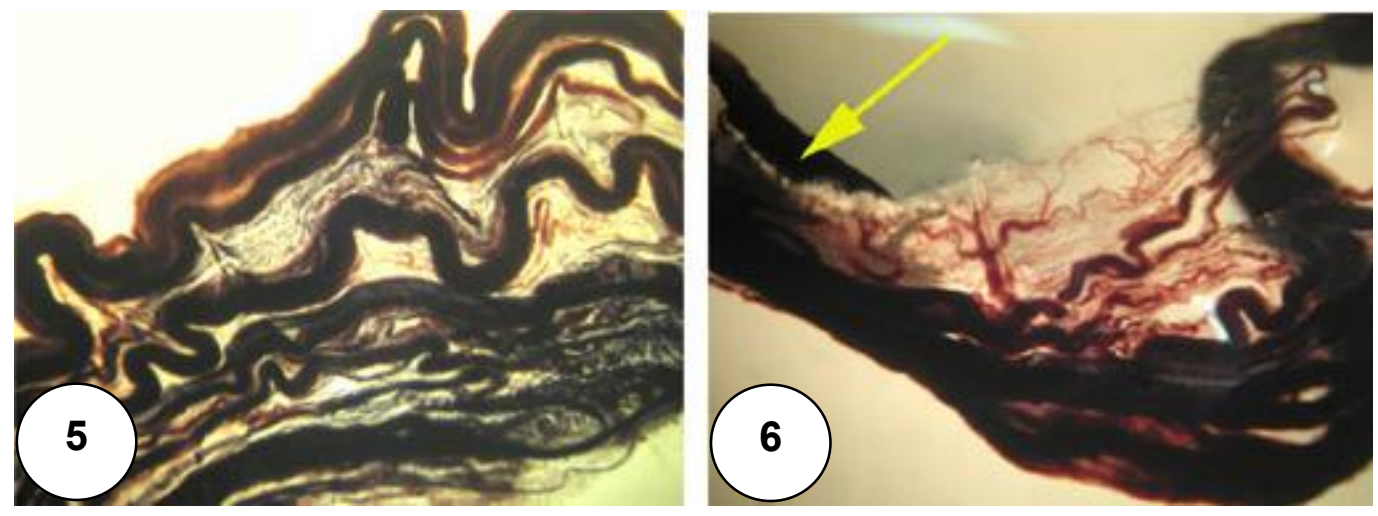

Fig (5): Photomacrograph of Indian ink serum injected sample showing the middle part of the lateral ventricle chroid plexus with straight, parallel and tortuous blood vessels. Using stereomicroscope $\mathrm{X} 8$

Fig (6): Photomacrograph of Indian ink serum injected sample showing the middle part of the lateral ventricle choroid plexus at the region of the narrow band (arrow), note the densely packed blood vessels. Using stereomicroscope X 8 

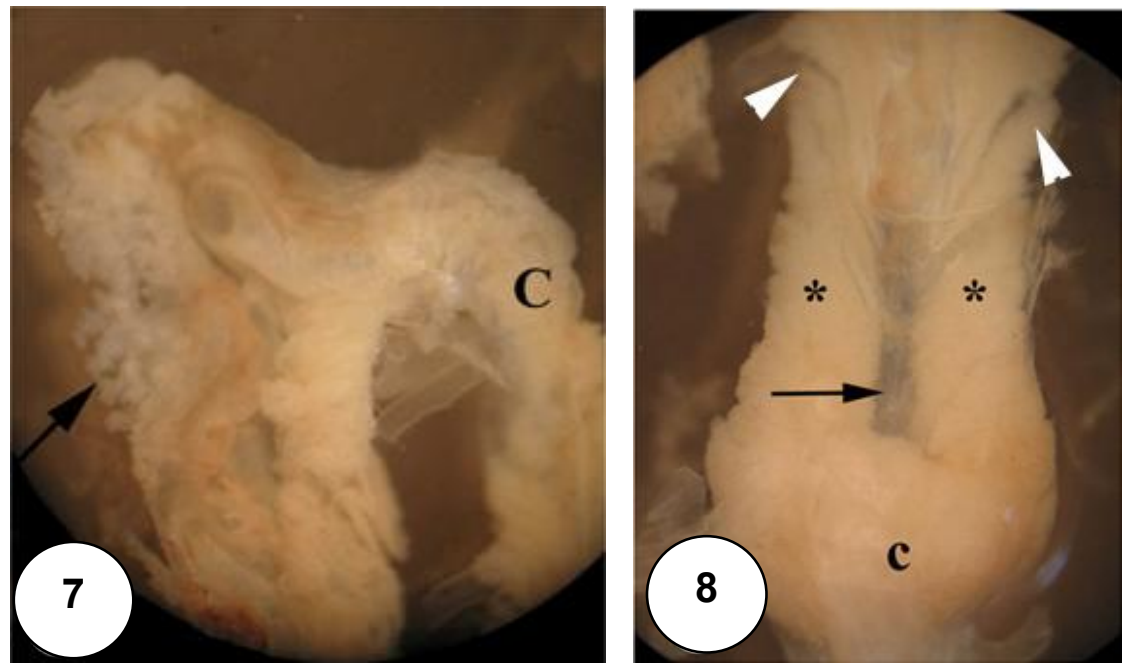

Fig (7): Photomacrograph of the rostral part of the lateral ventricle choroid plexus showing the villus fringes (arrow) and the narrow band (C). Using stereomicroscope X 6

Fig (8): Photomacrograph of the third ventricle choroid plexus (dorsal view) showing the rostral part as two narrow bands (asterisks), the down-folding linear tufts from them (arrow heads), dorsal longitudinal groove (arrow) and the thick caudal part (c ). Using stereomicroscope $\times 6$.
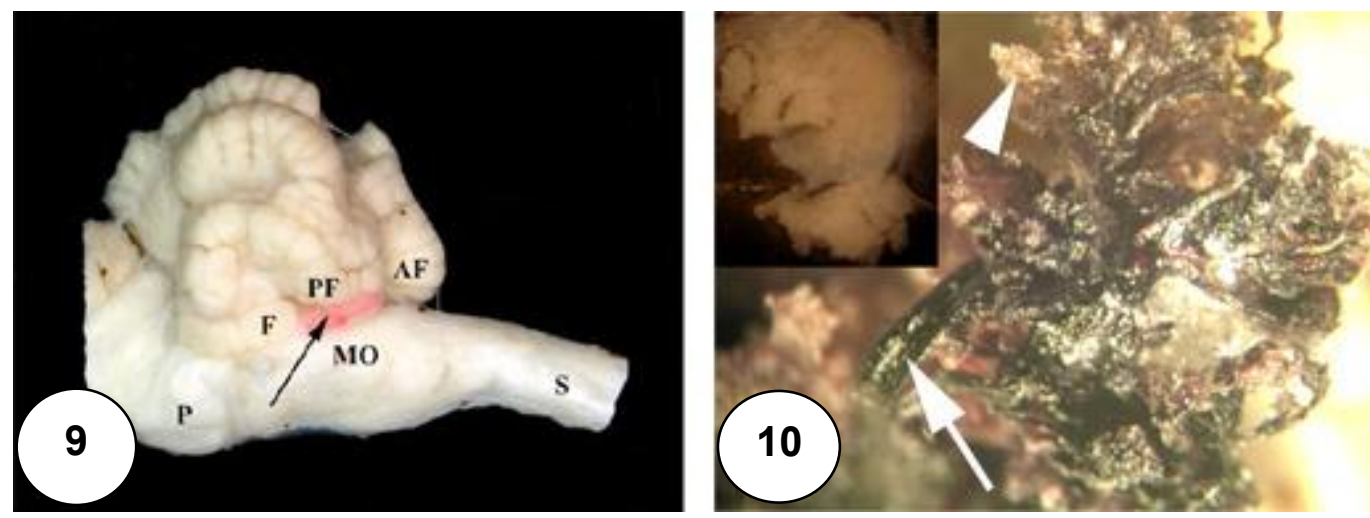

Fig (9): Photomacrograph of the caudal part of goat brain (lateral view) showing the choroid plexus of the fourth ventricle (arrow), medulla oblongata (MO), lobus follicularis $(F)$, lobus dorsalis parafollicularis (PF), lobus anisiformis (AF), pons (P) and spinal cord (S).

Fig (10): Photomacrograph of Indian ink serum injected sample showing the tree-like branching of the fourth ventricle choroid plexus, basal stem (arrow) and leaves (arrow head). Using stereomicroscope X10. Inset: formalized non injected sample. X 6 

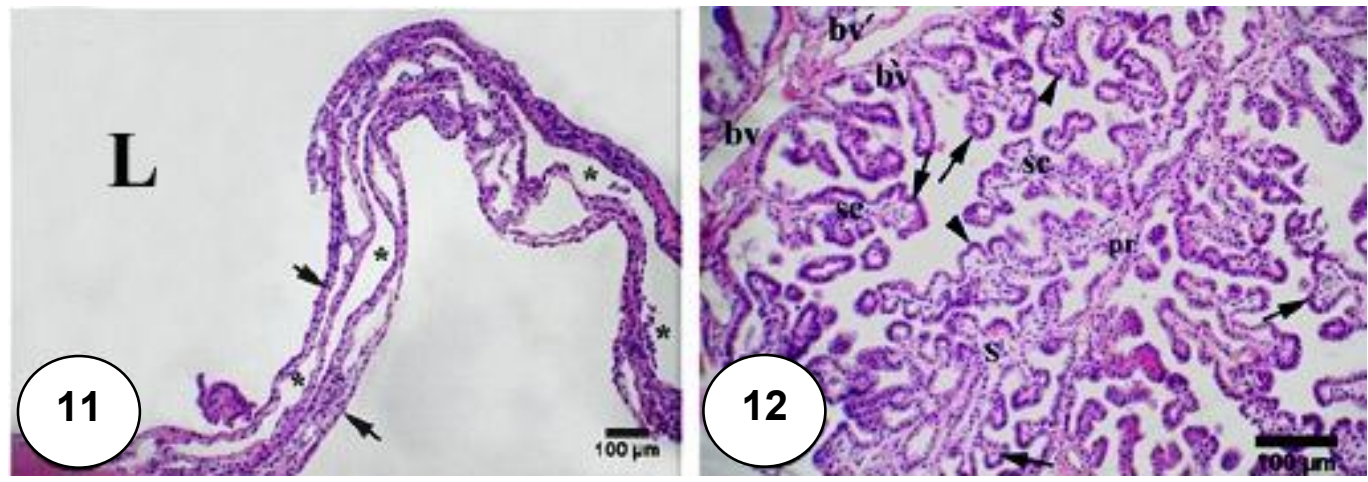

Fig (11): Photomicrograph (H\&E stain). of the choroid plexus of the lateral ventricle showing long parallel folds, covered with cuboidal epithelium (arrows), blood vessels (asterisk) and the lumen of the lateral ventricle (L) Scale bar $=100 \mu \mathrm{m}$

Fig (12): Photomicrograph (H\&E stain). of the choroid plexus of the third ventricle showing primary leaves (pr), secondary leaves (sc), leaves-like process (arrows), covering epithelium (arrow head), connective tissue stroma (s) and blood vessels (bv). Scale bar $=100 \mu \mathrm{m}$
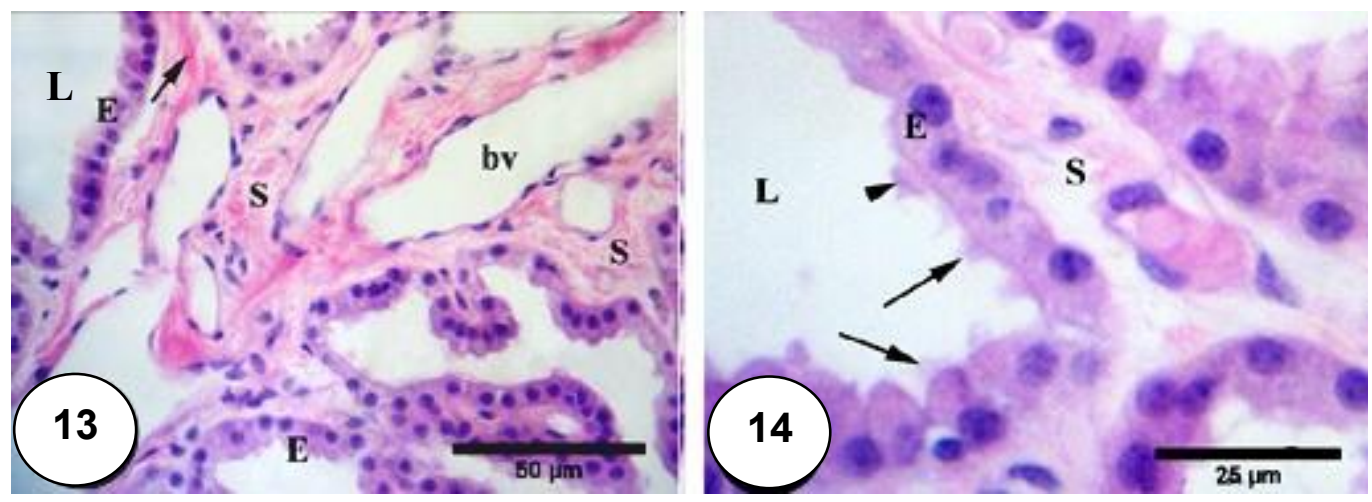

Fig (13): Higher magnification of (Fig. 12) showing the high cuboidal to low columnar covering epithelium $(E)$, connective tissue stroma $(S)$ with collagen bundles (arrow) blood vessels (bv) and the lumen of the third ventricle $(\mathrm{L})$. Scale bar $=$ $50 \mu \mathrm{m}$.

Fig (14): Photomicrograph (H\&E stain) of the choroid plexus of the lateral ventricle showing the cuboidal choroidal epithelium (E), with tuft of cilia (arrow) and bulged luminal border (arrow head) and the lumen of the third ventricle $(L)$. Scale bar $=25 \mu \mathrm{m}$. 

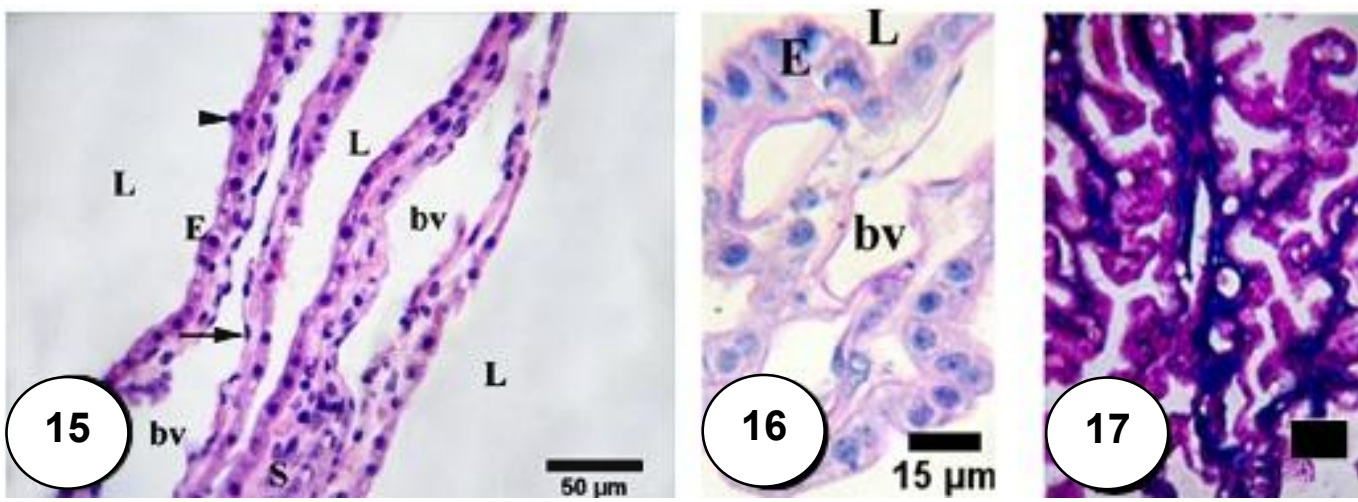

Fig (15): Higher magnification of (Fig. 11) showing, the covering cuboidal epithelium (E), the endothelial lining (arrow) of the blood vessels (bv), connective tissue stroma (S), epiplexus cell (arrow head) and the lumen of the lateral ventricle (L). Scale bar $=50 \mu \mathrm{m}$.

Fig (16): Photomicrograph (PAS-stained) of the choroid plexus of the fourth ventricle showing that the epithelium $(E)$ is faintly stained except for its apical border. The lumen of the fourth ventricle $(\mathrm{L})$ and the blood vessels (bv). Scale bar $=15$ $\mu \mathrm{m}$

Fig (17): Photomicrograph of the choroid plexus of the third ventricle displaying the blue-colored collagen bundles in the connective tissue stroma. (Masson's trichrom stain). Scale bar $=25 \mu \mathrm{m}$ 